\title{
Aspectos clínicos do entrópio de desenvolvimento em cães da raça Shar Pei
}

[Clinical aspects of developmental entropion in Shar Pei dogs]

\author{
F.A.B. Viana ${ }^{1}$, S. Cronemberger Sobrinho ${ }^{2}$, K.D.A. Borges ${ }^{1}$, G.D. Fulgêncio ${ }^{3}$ \\ ${ }^{1}$ Escola de Veterinária - UFMG \\ Caixa Postal 567 \\ 30123-970 - Belo Horizonte, MG \\ ${ }^{2}$ Faculdade de Medicina - UFMG \\ ${ }^{3}$ Unipac-Bom Despacho, MG
}

\begin{abstract}
RESUMO
Avaliaram-se os aspectos clínicos do entrópio de desenvolvimento em filhotes de cães da raça Shar Pei. Utilizaram-se 50 animais com idades entre 18 e 128 dias, que apresentavam graus variáveis de inversão palpebral e lesões oculares, as quais foram classificadas de acordo com um modelo específico proposto. As lesões encontradas foram fotofobia, epífora, inversão da margem palpebral, blefarospasmo, conjuntivite, quemose, edema, erosão e vascularização da córnea e phthisis bulbi.
\end{abstract}

Palavras-chave: cão, Shar Pei, doenças palpebrais, entrópio

\section{ABSTRACT}

The clinical aspects of entropion in puppies of the Shar Pei breed were studied using 50 animals, 18 to 128 day-old, that presented variable degrees of palpebral inversion and ocular lesions. The ocular lesions were classified according to a specific model. Photophobia, epiphora, palpebral margins inversion, blepharospasm, conjuntivitis, quemosis, corneal edema, erosion and vascularization and phthisis bulbi were observed.

Keywords: dog, Shar Pei, palpebral diseases, entropion

\section{INTRODUÇÃO}

A raça Shar Pei é originária da China e sua utilização atual é a defesa e guarda de propriedades. Dentre as várias características descritas pelo padrão da raça, destaca-se a presença de pêlo curto e áspero e a exigência de rugas sobre o crânio, especialmente na testa e bochechas. Preconiza ainda o padrão que o funcionamento do bulbo ocular ou das pálpebras não deve ser prejudicado por interferência da pelagem ou das dobras da pele e qualquer sinal de irritação do bulbo ocular, conjuntiva ou pálpebras é altamente indesejável (Confederação..., 2004).

Recebido em 9 de novembro de 2004

Aceito em 23 de agosto de 2005

E-mail: fbretas@vet.ufmg.br
A presença de rugas é marcante nos animais de até quatro meses. A partir dessa idade, o crescimento da pele deixa de acompanhar o do restante do corpo, e os cães perdem paulatinamente grande parte destas rugas, ficando as mesmas, na maioria das vezes, restritas à cabeça e membros posteriores.

A Federação Cinológica Internacional modificou, nos últimos tempos, vários padrões de raça, eliminando a exigência de características que possam ter reflexos negativos sobre a saúde dos animais. Assim, na última revisão do padrão da raça Shar Pei, foi abolida a exigência da 
presença de rugas por todo o corpo, ficando as mesmas restritas apenas à região da cabeça. A despeito desses esforços, os criadores continuam selecionando cães cada vez mais enrugados, pela sua comercialização mais fácil (Federation..., 2004).

As pálpebras caninas se fundem aos 32 dias de vida uterina, e a separação ocorre aproximadamente 10 a 14 dias após o nascimento (Cook, 1999; Slatter, 2001). Em geral, a maioria dos carnívoros apresenta esse anquilobléfaro fisiológico, necessário pela relativa imaturidade dos tecidos do olho e de seus anexos, incluindo a musculatura palpebral e o aparelho lacrimal, no momento do nascimento (Gum et al., 1999).

No olho canino normal, as pálpebras repousam sobre o bulbo ocular, e suas bordas livres estão fundidas nos cantos medial e lateral. A abertura limitada pelas pálpebras denomina-se fenda ou comissura palpebral, cuja forma característica é determinada pelos ligamentos palpebrais inseridos na parede orbitária (Samuelson, 1999). O tamanho da fenda palpebral varia de acordo com a raça, normalmente apresentando uma média de 32,7 $\pm 4,2 \mathrm{~mm}$ em cães adultos (Stades et al., 1992).

Pelo fato de a fenda palpebral não ser patente ao nascimento em algumas espécies, o termo congênito não pode ser empregado para várias doenças da pálpebra, mas apenas para algumas poucas realmente existentes nesta época como, por exemplo, anquilobléfaro persistente, agenesia palpebral e dermóides. As demais alterações, incluindo o entrópio, são classificadas como de desenvolvimento, pois são predeterminadas antes do nascimento, mas somente se manifestam clinicamente algum tempo após o mesmo, depois da abertura das pálpebras (Bedford, 1999).

Entrópio é uma inversão da margem palpebral, fazendo com que os cílios e pêlos entrem em contato com a conjuntiva e a córnea, causando sintomatologia variável entre discreto desconforto acompanhado por epífora a graus variáveis de lesão de conjuntiva e córnea, resultando em dor ocular intensa e constante (Bedford, 1999).

O entrópio é mais freqüente em cães, eqüídeos e ovinos, mas há descrição da alteração em várias outras espécies (Peiffer et al., 1980). Nos cães, entrópio e ectrópio são consideradas as mais amplamente distribuídas doenças palpebrais, com o envolvimento de várias raças (Willis, 1989).

O entrópio é classificado como um defeito de desenvolvimento (primário) ou uma lesão adquirida (secundário), resultante de outras alterações oculares, podendo haver uma superposição entre as duas situações (Bedford, 1999). Alguns autores incluem um terceiro tipo, o entrópio espástico, resultante de dor ocular crônica. A diferenciação entre a espasticidade presente nos demais tipos e a existência em um eventual entrópio espástico primário é motivo de controvérsia entre os pesquisadores (Gelatt, 2003).

O entrópio de desenvolvimento apresenta grau variável de comprometimento da pálpebra e, dependendo da extensão da rotação da margem palpebral, pode ser classificado em leve $\left(45^{\circ}\right)$, moderado $\left(90^{\circ}\right)$ ou grave $\left(180^{\circ}\right)$. Quanto à posição da rotação na pálpebra, o entrópio pode ser medial, angular ou total e afetar a pálpebra superior e/ou inferior (Stades et al., 1999).

Rougraff et al. (2001), ao descreverem o entrópio involucional humano, sugeriram sua classificação com base na lesão corneana produzida em: (1) sem lesão, (2) erosões puntiformes discretas, (3) erosões puntiformes múltiplas e (4) defeito epitelial bem definido.

Petersen-Jones (1999) considera o entrópio de desenvolvimento nos cães como uma doença não-congênita hereditária. Bouw (1991) afirma que este tipo de entrópio é uma alteração poligênica influenciada pela seleção dos animais e sugere a modificação dos padrões raciais como forma de reduzir sua incidência. A maioria dos entrópios de desenvolvimento demonstra clara predisposição racial, mas a base genética não é claramente entendida. Em algumas raças, a alteração apresenta-se isoladamente, mas em muitas outras, entretanto, fatores anatômicos predisponentes devem ser considerados. Para Stades et al. (1999), o entrópio primário resulta da diferença de tensão entre os músculos orbicular do olho e malar, sendo ainda influenciado por inúmeras condições, como conformação do crânio, anatomia da órbita e quantidade de pregas na pele da face ao redor do 
olho. Afirmam ainda que, na maioria dos casos, é resultante de um defeito hereditário, possivelmente uma condição poligênica.

A predisposição à doença ocorre em várias raças, e a maioria dos casos primários apresenta os primeiros sinais clínicos antes dos seis meses de idade, mas ocasionalmente um entrópio espontâneo e às vezes unilateral pode apresentarse após os 12 meses (Bedford, 1999).

Stades et al. (1992) demonstraram que a fenda palpebral de animais portadores de entrópio é significativamente maior quando comparada à de cães da mesma raça com pálpebras normais. Fatores predisponentes importantes, relacionados à facilidade com que a pálpebra pode se inverter, incluem a relação entre as pálpebras e o bulbo ocular, que são representados pelo tamanho do bulbo e sua posição na órbita, tamanho da fenda palpebral e tônus do músculo orbicular do olho. A lassidão da fenda palpebral determina distorções palpebrais, e fendas grandes podem predispor ao desenvolvimento de entrópio ou ectrópio. Indubitavelmente, a lassidão da pele circunorbital e a presença de rugas faciais contribuem para a deformação das pálpebras na raça Shar Pei (Bedford, 1999). A ausência de uma placa tarsal bem definida nos carnívoros resulta em falta de rigidez palpebral e requer um contato estrito da pálpebra com o bulbo para que a mesma se mantenha corretamente posicionada; olhos enoftálmicos podem também apresentar entrópio pela ausência de contato da pálpebra inferior com o bulbo ocular (Gelatt, 1994).

Por ser uma doença de caráter genético, a prevenção do entrópio de desenvolvimento é baseada na eliminação de animais portadores de programas de reprodução, evitando-se a transmissão da mesma (Stades et al., 1999). Leppänen et al. (1999) atribuem uma grande importância ao papel desempenhado por médicos veterinários e entidades cinófilas junto aos criadores, no sentido de conscientizá-los da seriedade das doenças geneticamente transmitidas e das medidas para sua prevenção.

Clinicamente, o entrópio manifesta-se através de fotofobia, epífora, blefarospasmo e hiperemia conjuntival, com as bordas palpebrais apresentando-se irritadas e brancacentas pelo contato constante com a lágrima. Com a evolução do quadro, aparece uma conjuntivite purulenta, e a córnea apresenta edema, ulceração e vascularização; a dor ocular intensa pode determinar miose no animal (Slatter, 2001). Em qualquer entrópio, o defeito primário causa irritação trigeminal, fazendo com que grande parte do quadro clínico seja produzido por espasticidade palpebral (Bedford, 1999).

O entrópio pode ser acompanhado de formação de cicatrizes e perda de tonicidade do músculo orbicular do olho. Algumas lesões corneanas resultantes cicatrizam-se através de tecido de granulação, com conseqüente perda da transparência corneana, ou aprofundam-se até que ocorra a perfuração. Vários animais portadores de entrópio de desenvolvimento não tratado apresentam phthisis bulbi (Bedford, 1999; Stades et al., 1999; Viana, 2002).

Propôs-se com este estudo a observação das características genéticas e aspectos clínicos do entrópio de desenvolvimento em Shar Peis.

\section{MATERIAL E MÉTODOS}

Utilizaram-se 50 cães da raça Shar Pei, com idade variável entre 18 e 128 dias, portadores de entrópio em graus variáveis. Obteve-se inicialmente um histórico completo, com ênfase na eventual ocorrência de entrópio nos pais e em irmãos de ninhadas anteriores. Os animais foram clinicamente examinados, a fim de se verificar a integridade das funções vitais e a ausência de doenças sistêmicas. Realizou-se ainda minucioso exame das pálpebras, conjuntiva e córnea, através de iluminação focal, oftalmoscópio direto $^{1}$ e lâmpada de fenda ${ }^{2}$. Para a classificação do grau de inversão palpebral e severidade do quadro clínico, baseou-se no proposto por Stades et al. (1999) e Rougraff et al. (2001) com modificações, consistindo de: a) grau de inversão palpebral: 1 (terço ou metade lateral da pálpebra superior envolvida), 2 (toda a pálpebra superior envolvida) ou 3 (pálpebras superior e inferior envolvidas); b) severidade do quadro clínico: 1 (fotofobia, epífora e triquíase), $2(1+$ blefarospasmo, conjuntivite e quemose), 3 (2+ edema corneano $), 4(3+$ ulceração e vascularização corneanas) e 5 (4+ enoftalmia).

\footnotetext{
${ }^{1}$ Oftalmoscópio direto beta 200 - Heine

${ }^{2}$ Lâmpada de fenda - Carl Zeiss
} 


\section{RESULTADOS}

Todos os animais apresentavam o padrão morfológico característico dos cães molossóides, com crânio volumoso tendendo a cúbico e órbitas profundas. Destacava-se a presença de rugas abundantes em toda a região da cabeça, notadamente na face e na região occipital. Os olhos eram proporcionalmente pequenos em relação à órbita, determinando má justaposição da pálpebra ao bulbo e falsa aparência de enoftalmia. Não se observou qualquer sinal de lassidão da fenda palpebral, mas sim uma pele muito espessa, como é característico nos Shar Peis.

Durante a anamnese, observou-se que muitos animais eram filhos de cães portadores de entrópio, mas alguns deles tinham pais com pálpebras normais. Em uma mesma ninhada, observaram-se filhotes com entrópio e outros normais, havendo também, em alguns casos, variação no grau de comprometimento palpebral de cada um deles.

Constatou-se entrópio bilateral com envolvimento da pálpebra superior em todos os animais, sendo que 14 deles (28\%), com idade superior a 30 dias, também exibiam a alteração na pálpebra inferior. Quarenta e oito cães (96\%) apresentaram inversão de toda a margem palpebral, e apenas dois (4\%) tinham comprometimento restrito ao terço lateral. Utilizando-se o modelo de classificação proposto, observaram-se dois animais com grau 1 de entrópio (inversão do terço ou metade lateral da pálpebra superior), 34 com grau 2 (inversão completa da pálpebra superior) e 14 com grau 3 (inversão completa das pálpebras superior e inferior). A correlação entre o grau de inversão palpebral e a idade dos animais mostrou que o envolvimento da pálpebra inferior só ocorreu em animais acima de 30 dias de idade.

Ao exame oftalmológico, observaram-se fotofobia e epífora em todos os cães e triquíase naqueles cuja inversão palpebral era total $(96 \%)$. Os demais sinais clínicos observados foram conjuntivite e quemose $(68 \%)$, edema corneano $(44 \%)$, blefarospasmo $(42 \%)$, erosão corneana (36\%), vascularização corneana (26\%) e enoftalmia (18\%). Todos os animais que apresentavam erosão corneana mostravam ainda miose resultante da dor ocular crônica. Três animais, com idades de 105, 107 e 128 dias, apresentaram córneas com extenso leucoma.

Os achados dos exames clínicos e a classificação dos entrópios são apresentados na Tab. 1.

\section{DISCUSSÃO E CONCLUSÕES}

A utilização do termo "entrópio de desenvolvimento", conforme sugerido por Bedford (1999), mostrou-se adequado, pois realmente seria incorreto classificar-se a alteração como congênita quando a mesma não é patente ao nascimento, devido ao anquilobléfaro fisiológico apresentado pelos cães.

A freqüência de alterações palpebrais foi diretamente proporcional à pureza racial dos cães. Os animais mais enquadrados no padrão racial preconizado pela Federation Cynologique Internationale (Federation..., 2004), pela presença abundante de rugas nas regiões facial e occipital, exibiram alterações palpebrais mais exuberantes que os demais. Essa observação contradiz o próprio padrão oficial da raça, que considera como falta desqualificante qualquer interferência da pele e pêlos no bulbo ocular. A modificação dos padrões raciais citada por Bouw (1991) e a conscientização dos criadores por parte de entidades cinófilas e médicos veterinários, sugerida por Leppänen et al. (1999), exerceriam importante papel no controle dessas alterações.

Segundo Bedford (1999) e Stades et al. (1999), fatores predisponentes relacionados à facilidade com que a pálpebra pode se inverter são extremamente importantes na etiopatogenia do entrópio em Shar Peis. A presença de órbitas profundas, rugas abundantes na região da cabeça e olhos proporcionalmente pequenos, determinando má justaposição da pálpebra ao bulbo, constituem fatores predisponentes ao desenvolvimento do entrópio, aspecto já descrito por Gum et al. (1999). Entretanto, nos filhotes não se observou qualquer sinal de lassidão da fenda palpebral, como sugerido por Bedford (1999). Ao contrário, os animais apresentavam, como é característico na raça, uma pele muito espessa quando comparada à das demais raças que, juntamente com o pêlo curto e áspero, constitui um fator agravante do quadro de entrópio, pela maior abrasão corneana produzida. 
Viana et al.

Tabela I. Identificação, classificação e sinais clínicos do entrópio em cães da raça Shar Pei

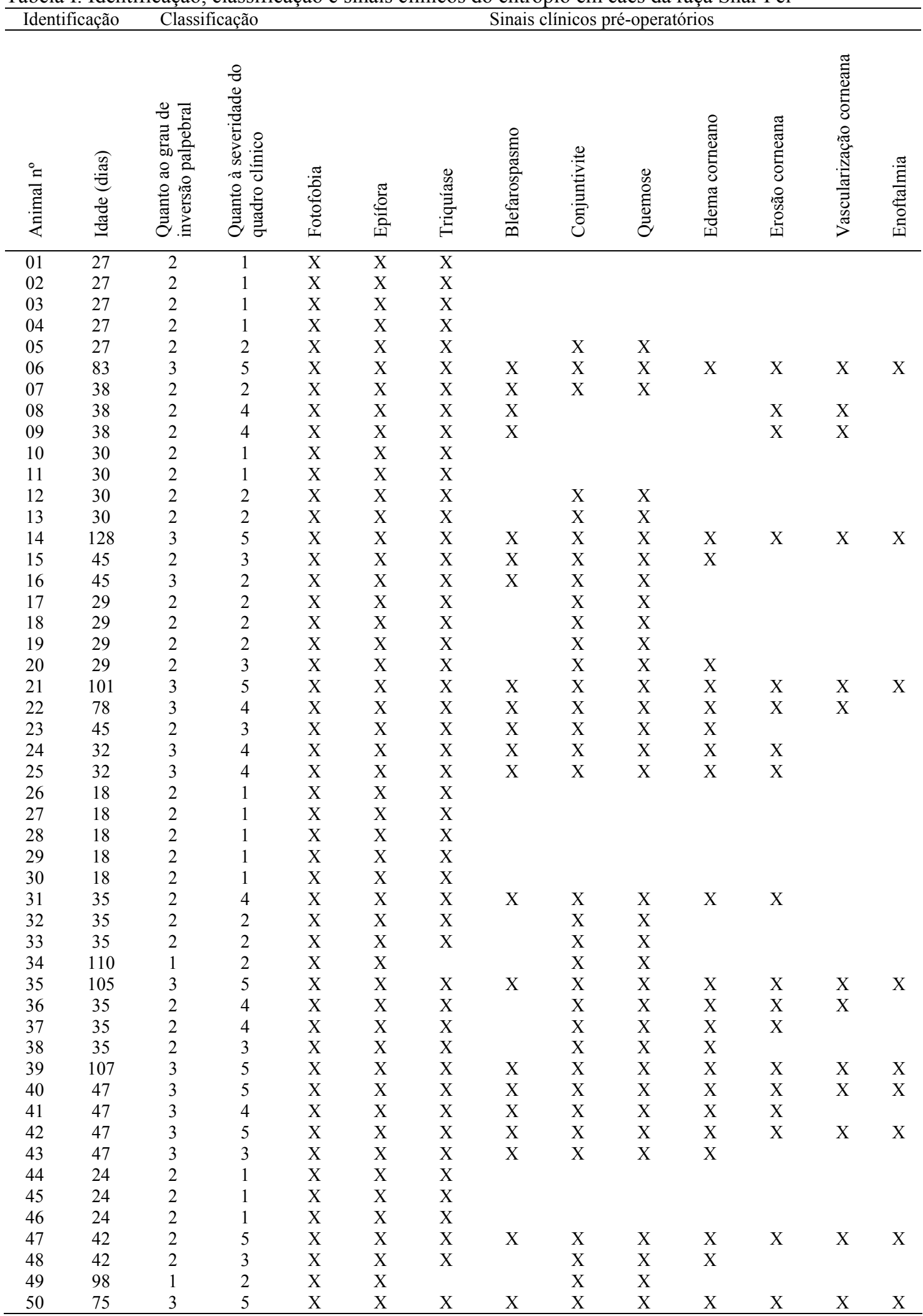


A classificação utilizada, resultante da modificação das propostas de Rougraff et al. (2001) e Stades et al. (1999), permitiu categorizar os entrópios de acordo com o grau de inversão palpebral e a severidade do quadro clínico de maneira didática, apresentando dados facilmente utilizáveis em modelos estatísticos.

Todos os animais examinados apresentavam entrópio bilateral, comprovando os achados de Gelatt (2003). Igualmente em conformidade com este autor e com Stades et al. (1999), observou-se entrópio na pálpebra superior de todos os cães, sendo que 14 deles (28\%) exibiram também comprometimento da pálpebra inferior. Estes últimos 14 animais tinham idade superior a 30 dias, permitindo concluir que o entrópio inferior era espástico, resultante da dor ocular crônica produzida pela inversão da pálpebra superior, como descrevem Stades et al. (1999).

Os resultados dos exames oftalmológicos coincidem com os de Slatter (2001) e Gelatt (2003). A presença de leucoma nos animais mais velhos confirma os relatos de Bedford (1999), Stades et al. (1999) e Viana (2002). Quando se associam os sinais clínicos à idade dos animais, observou-se que a severidade das alterações oculares foi diretamente proporcional à idade, permitindo, mais uma vez, destacar a importância do componente espástico no agravamento do quadro, conforme descrito por Bedford (1999).

\section{REFERÊNCIAS BIBLIOGRÁFICAS}

BEDFORD, P.G.C. Diseases and surgery of canine eyelid. In: GELATT, K.N. (Ed.). Veterinary ophthalmology. 3.ed. Philadelphia: Lippincott Williams \& Wilkins, 1999. p.535-568.

BOUW, J. Genetic eye defects in the dog. Tijdsch. Diergen., v.116, p.898-905, 1991.

CONFEDERAÇÃO BRASILEIRA DE CINOFILIA. Padrões de raça. Disponível em $<$ http://www.cbkc.org/relracag2.html $>$. Acessado em 14 de janeiro de 2004.

COOK, C.S. Ocular embryology and congenital malformations. In: GELATT, K.N. (Ed.). Veterinary ophthalmology. 3.ed. Philadelphia: Lippincott Williams \& Wilkins, 1999. p.3-30.
FEDERATION CYNOLOGIQUE INTERNATIONALE. Standars \& Nomenclature. Disponível em <http://www.fci.be/nomenclatures $>$. Acessado em 14 de janeiro de 2004.

GELATT, K.N. Handbook of small animal ophthalmic surgery volume 1: extraocular procedures. London: Elservier Science, 1994. 195p.

GELATT, K.N. Manual de oftalmologia veterinária. São Paulo: Manole, 2003. 594 p.

GUM, G.G.; GELATT, K.N.; OFRI, R. Physiology of the eye. In: GELATT, K.N. (Ed.). Veterinary ophthalmology. 3.ed. Philadelphia: Lippincott Williams \& Wilkins, 1999. p.151-181.

LEPPÄNEN, M.; PALOHEIMO, A.; SALONIEMI, H. Attitudes of finnish veterinarians about programs to control canine genetic diseases. Prev. Vet. Med., v.38, p.239-257, 1999.

PEIFFER, R.L.; JOHNSON, P.T.; WILKERSON, B.J. Peripalpebral folds and entropion in a male crab-eating macaque (Macaca fascicularis). Lab. Anim. Sci., v.30, p.113-115, 1980.

PETERSEN-JONES, S. Clinical and molecular genetics. In: GELATT, K. N. (Ed.). Veterinary ophthalmology. 3.ed. Philadelphia: Lippincott Williams \& Wilkins, 1999. p.219-238.

ROUGRAFF, P.M.; TSE, D.T.; JOHNSON, T.E. et al.Involutional entropion repair with fornix sutures and lateral strip procedures. Opht. Plastic Reconst. Surg., v.17, p.281-287, 2001.

SAMUELSON, D.A. Ophthalmic anatomy. In: GELATT, K.N. (Ed.). Veterinary ophthalmology. 3.ed. Philadelphia: Lippincott Williams \& Wilkins, 1999. p.31-150.

SLATTER, D.H. Fundamentals of veterinary ophthalmology. 3.ed. Philadelphia: W.B. Saunders, 2001. 640p.

STADES, F.C.; BOEVÉ, W.N.; NEUMANN, W. et al. Fundamentos de oftalmologia veterinária. São Paulo, Manole, 1999. 204p.

STADES, F.C.; BOEVÉ, W.N.; WOERDT, A. Palpebral fissure length in the dog and cat. Prog. Vet. Comp. Ophtalmol., v.2, p.155-161, 1992.

VIANA, F. A. B. Cadernos didáticos: fundamentos de oftalmologia clínica. Belo Horizonte: FEPMVZ Editora, 2002. 132p.

WILLIS, M.B. Genetics of the dog. New York: Howell Book House, 1989. 417p. 